\title{
IMPORTANCE OF ACOSUTIC EMISSION BASED $b$-VALUE IN THE STUDY OF FRACTURE PROCESS IN REINFORCED CONCRETE STRUCTURES
}

\author{
R. VIDYA SAGAR \\ *Department of Civil Engineering \\ Indian Institute of Science, Bangalore, India-560 012 \\ e-mail: rvsagar@civil.iisc.ernet.in
}

Key words: Reinforced Concrete, Acoustic emission, $b$-value

\begin{abstract}
This article reports on importance of acoustic emission (AE) based $b$-value in the study of fracture process in reinforced concrete (RC) structures. The significance of amplitudedistribution and $b$-value (slope of the line plotted using log-linear frequency-amplitude relation) of acoustic emissions released ahead of the failure of reinforced concrete beams of $2.6 \mathrm{~m}$ span are presented. The experiments were conducted in incremental cyclic loading under load control and simultaneously the released AE, strain in tensile steel, displacement at midspan were recorded. The effect of loading rate, compressive strength of concrete on variation in $\mathrm{AE}$ based $b$-values with the development of cracks in RC structures were studied. The average $b$-values are lower as a few but larger amplitudes of $\mathrm{AE}$ events occurred in contrast to more number of low amplitude AE events observed at low loading rates (or at low strain rates). Moreover, the $b$-values are compared to the strain in steel and the evolution of cracks on the specimen to assess the damage state. It is observed that when the loading rate is higher, quick cracking development lead to rapid fluctuations and drops in the $b$-values.
\end{abstract}

\section{INTRODUCTION}

In seismology, an empirical formula proposed by Gutenberg-Richter given in Eq. (1) is used for $b$-value analysis [1-2].

$$
N(\geq m)=10^{a-b m}
$$

where $N$ is the cumulative number of earthquakes of magnitude $\geq m$ in a particular area over a specified time span, $a$ and $b$ are constants which vary with the region. In context of $\mathrm{AE}$ monitoring technique, the Gutenberg-Richter formula is given in Eq. (2) [3].

$$
\log _{10} N=a-b\left(\frac{A_{d B}}{20}\right)
$$

where $N$ is the number of $\mathrm{AE}$ hits with an amplitude higher than $A_{d B} . \quad a$ is a constant determined largely by the background noise present in the surroundings of testing and $b$ is the negative slope of the curve plotted between $\log _{10}(N)$ and AE signal amplitude $\left(A_{d B}\right)$.

Several researchers working in the area of civil engineering studied the applicationof $\mathrm{AE}$ frequency-amplitude distribution analysis releated to RC structures [4-12]. According to researchers working in the area of seismology and rock mechanics the $b$-value decreases before the occurrence of an earthquake. It was observed that the $b$-value is inversely related to the accumulation of stress in a given region. Analogous to $\mathrm{AE}$ technique, the $b$-value represents the scaling of $\mathrm{AE}$ amplitude distribution and is an appearance of identical features at different scales for micro-seismicity during fracture process in RC structures. Therefore, during fracture process in $\mathrm{RC}$ structures a decreasing $b$-value could be 
indicative of increasing stress levels or an indication of an impending fracture. Thus, the $b$-value is a useful tool for assessing damage status. In fact, recording of all released $\mathrm{AE}$ waves during monitoring of fracture process in $\mathrm{RC}$ structures is a difficult task. Therefore, a statistical approaches such as $b$-value analysis is needed. Aim is to study the influence of loading rate and comcpressive strength of concrete on AE based $b$-values.

\section{EXPERIMETNAL PROCEDURE}

\subsection{Materials and test specimens}

A total of sixteen RC flanged beam (T-beam cross section) specimens were tested and the geometry, concrete mixture, steel reinforcement details and loading conditions are given in Table 1 and in the same table $n$ is number of reinforcement bars; $b$ is beam width; $D$ is beam depth; $A_{s}$ is \% of crosssection of steel reinforcement. A specimen in the test rig and reinforcement details are shown in Figure 1. During testing a RC specimen was loaded at mid-span and simply supported over a span $S$. The length of the test speicmen is $3.2 \mathrm{~m}$. The loading was conducted by means of a four-point bending configuration [13].

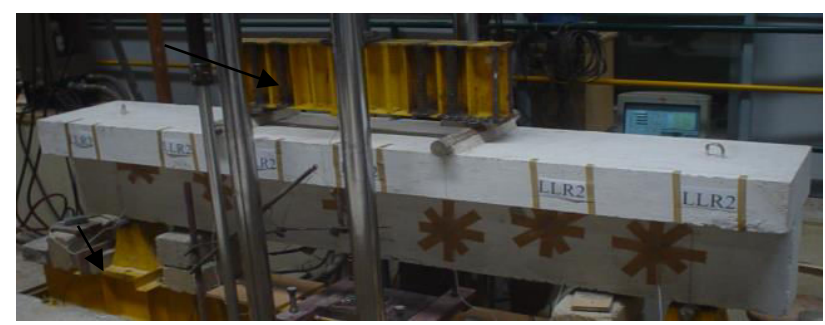

Figure 1: RC flanged beam specimen in the test rig, Structures laboratory, Department of Civil Engineeirg, Indian institute of Science, Bangalore.

Two-point loading span was $1 \mathrm{~m}$ with $2.6 \mathrm{~m}$ supporting-span.

\subsection{Testing arrangement}

The experimental setup consisted of a servo hydraulic loading machine $(1200 \mathrm{kN})$ with a data acquisition system and a $\mathrm{AE}$ monitoring system. A Steel beam (I-cross section) was placed beneath the actuator of the loading machine to transfer the load as two point load son the test specimen. The load was applied (in four point bending) in incremental cycles till failure of the specimen. The data acquisition records load, displacement at center of the beam, strain in the steel at the centre of the RC beam and time. The mid-span displacement was measured using a linearly varying displacement transformer placed at the center on the underside of the RC beam. The strain in steel at mid section of the test specimen is recorded using electrical strain gauge which was fixed to main steel reinforcing bar (tensile reinforcement) before casting of the specimen.

\subsection{AE monitoring system}

The AE monitoring system had eight channels one for each of the eight resonant type $\mathrm{AE}$ differential sensor, pre-amplifiers, data acquisition system, processing instrumentation. The $\mathrm{AE}$ transducer has peak sensitivity at $75 \mathrm{~dB}$ with reference $1 \mathrm{~V} /(\mathrm{m} / \mathrm{s})$. The operating frequency of the sensor was 35 $\mathrm{kHz}-100 \mathrm{kHz}$. The response was almost same for all sensors used in this study. The threshold value of $40 \mathrm{~dB}$ was selected to ensure a high signal to noise ratio.

\subsection{Loading procedure adopted}

The loading pattern applied on the RC beam (assumed as a beam in a bridge) is shown in Figure 2. The idea of loading protocol was to simulate traffic on a bridge beam. In a realsituation, it is required to collect moving vehicles data for designing the various structural members in a bridge. A real bridge would have experienced many smaller servicelevel loads as well as due to unknown higher overloads. In this present study a series of service-level load cycles are applied in between test trucks (TTs). These test trucks were chosen to represent the case of structural load testing in the field. TTs were variable in 
Table 1: Test specimen geometry, material and loading rate details.

\begin{tabular}{|c|c|c|c|c|c|c|c|c|c|c|}
\hline Specimen & $n$ & $\begin{array}{c}A_{s} \\
\left(\mathrm{~mm}^{2}\right)\end{array}$ & $\begin{array}{l}\text { Concrete } \\
\text { mixture } \\
\text { grade } \\
\left(\mathrm{N} / \mathrm{mm}^{2}\right)\end{array}$ & $\begin{array}{c}W_{f} \\
(\mathrm{~mm})\end{array}$ & $\begin{array}{c}D \\
(\mathrm{~mm})\end{array}$ & $\begin{array}{c}b_{w} \\
(\mathrm{~mm})\end{array}$ & $\begin{array}{c}d_{w} \\
(\mathrm{~mm})\end{array}$ & $\begin{array}{l}\text { Failure } \\
\text { type }\end{array}$ & $\begin{array}{c}\text { Rate } \\
\text { of loading } \\
(\mathrm{kN} / \mathrm{s})\end{array}$ & Remarks \\
\hline LC1M37 & 4 & 1256 & 37 & 500 & 560 & 180 & 380 & Flexural & 4 & \multirow{2}{*}{ Change in mix grade } \\
\hline LC2M37 & 4 & 1256 & 37 & 500 & 560 & 180 & 380 & Flexural & 4 & \\
\hline LC3M60 & 4 & 1256 & 60 & 500 & 560 & 180 & 380 & Flexural & 4 & \multirow{2}{*}{ Change in mix grade } \\
\hline LC4M60 & 4 & 1256 & 60 & 500 & 560 & 180 & 380 & Flexural & 4 & \\
\hline LC5M80 & 4 & 1256 & 80 & 500 & 560 & 180 & 380 & Flexural & 4 & \multirow{2}{*}{ Change in mix grade } \\
\hline LC6M80 & 4 & 1256 & 80 & 500 & 560 & 180 & 380 & Flexural & 4 & \\
\hline SBF1 & 3 & 942 & 37 & 500 & 400 & 150 & 250 & Flexural & 4 & \multirow{2}{*}{ Change in depth } \\
\hline SBF2 & 3 & 942 & 37 & 500 & 400 & 150 & 250 & Flexural & 4 & \\
\hline LBF1 & 4 & 1256 & 37 & 500 & 560 & 180 & 380 & Flexural & 4 & \multirow{3}{*}{ Change in $\%$ of steel } \\
\hline LBF2 & 3 & 942 & 37 & 500 & 560 & 180 & 380 & Flexural & 4 & \\
\hline LBF3 & 2 & 628 & 37 & 500 & 560 & 180 & 380 & Flexural & 4 & \\
\hline LSF1 & 4 & 1256 & 37 & 500 & 560 & 180 & 380 & Shear & 4 & \multirow{2}{*}{ Shear failure } \\
\hline LSF2 & 4 & 1256 & 37 & 500 & 560 & 180 & 380 & shear & 4 & \\
\hline LLR1 & 4 & 1256 & 37 & 500 & 560 & 180 & 380 & Flexural & 6 & \multirow{3}{*}{ Change in loading rate } \\
\hline LLR2 & 4 & 1256 & 37 & 500 & 560 & 180 & 380 & Flexural & 5 & \\
\hline LLR3 & 4 & 1256 & 37 & 500 & 560 & 180 & 380 & Flexural & 5 & \\
\hline
\end{tabular}

loading magnitude. The smaller load repetitions indicative of service level loads. From Figure 2 one can observe that a series of TTs was repeated. The reason for this is to study the effect of repetitions on the $\mathrm{AE}$ response.

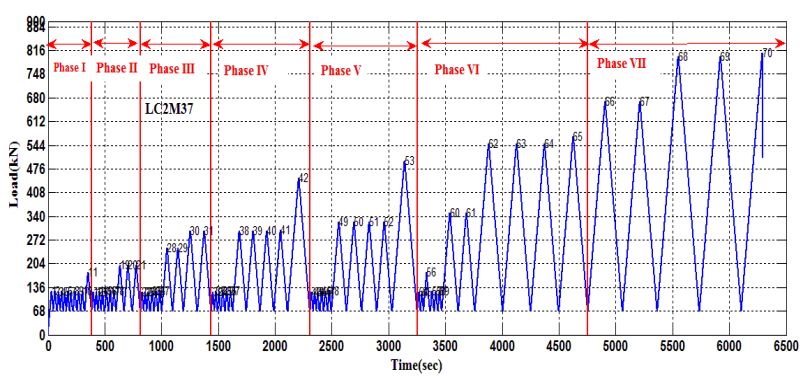

Figure 2: The loading protocol used to test the RC beam test specimen (LC2M37).

It is known that $\mathrm{AE}$ signals are unique and thus theoretically not repeatable. The RC beam specimen is subjected to loading protocol which has two types of pattern. The first pattern has load intensity with relatively less peak and constitutes transport hicle effect. The second pattern has higher peak load which constitutes elevated simulated test truck. The two patterns together give single loading phase. Each phase has varying load peaks. The loading rates used for the $\mathrm{RC}$ specimens are different as shown in Table-1 and this was intentional.

\section{RESULTS AND DISCUSSION}

In the present study $\mathrm{AE} b$-value was computed for each 125 hit amplitudes forward in time. Figure 3 shows the variation of $\mathrm{AE}$ based $b$ value with load. It is observed that a sudden drop in $b$-values occur at the peak load in each load cycle. The damage growth is characterized by the progressive coalescence of microcracks to form fracture surfaces.

During a loading process, the damage growth is characterized by the progressive coalescence of microcracks to form fracture surfaces. Because cracks at the beginning of the loading process are mainly distributed in the bulk of 
the material. In the initial stages of fracture process, the $b$-value varied from 1.5 to 1.8 and later it decreases with increase in load (or stress) equal to 1.0 and less, showing temporal fluctuations as the impending failure approaches in the $\mathrm{RC}$ beam specimen.

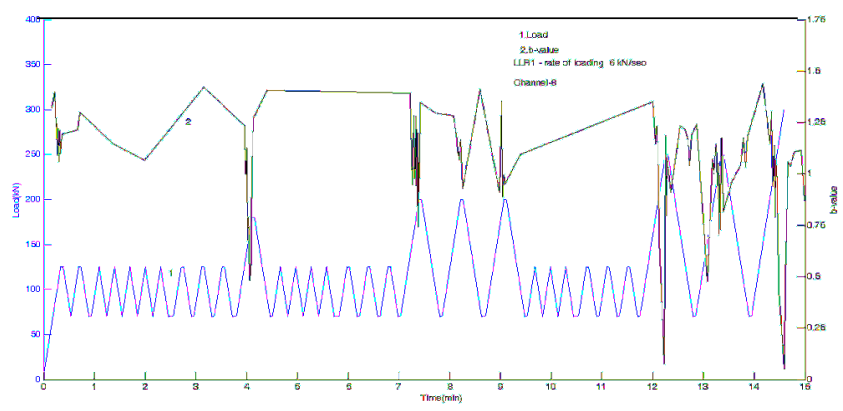

Figure 3: The variation of AE based $b$-value with load [channel 8 and LLR1 specimen]

A high $b$-value arises due to low amplitude hits in large number representing new crack formation and slow crack growth, whereas a low $b$-value indicates faster or unstable crack growth accompanied by relatively high amplitude AE in small numbers. Therefore the low $b$-value trend indicates macrocracks have formed, whilst the high $b$-value trend represents microcrack growth. During the first loading cycle, high $b$-values were observed with the opening of micro-cracks. Later $b$ values, showed a decrease as the load increased. The second loading phase was characterized by a large scatter of $b$-values.

The RC test specimen (LLR3) is relatively of large length (more than $3 \mathrm{~m}$ ). Therefore, several fractur events may occur simultaneously. It is known that the shear cracks follow tensile cracks. The recorded AE data is grouped according to the position of AE sensors. AE sensors S1 (or Ch-1) and S8 (or Ch-8) are in the shearing area away from the mid-span and therefore, S1 and S8 reasonably receive $\mathrm{AE}$ hits at the moments of development of shear cracks. On the other hand $\mathrm{AE}$ sensor $\mathrm{S} 3$ is in the center so it recorded information from the tensile cracks from bottom to top. As an example at the moments when the shear cracks develop, the near by sensors (S1 and S8) receive high intensity AE signals. However, possibly the central or other far away sensors may not get similar activity. Therefore, it was attempted to check the $b$-value for different sensors separately, and compared with strain in steel at mid section of the specimen LLR3.

Earlier researchers confirmed that a $b$-value less than 1.0 represents macro-damage (visible cracks). It was observed that there are several drops (or fluctuations) in $b$-value computed based on Ch-3 when compared to Ch- 1 and Ch-8. This may be due to several tensile cracking occurred before occurrence of shear cracks. The $b$-value dropped below 1.0 at the end of the loading phase-I. The load magnitude associated with appearance of first tensile crack appeared is $137 \mathrm{kN}$ in moment zone. At around 30 minutes, the $b$-value showed a significant drop indicating that more damage occurred, and it is noted that noticeable cracking occurred. The lowest $b$ value was recorded during last loading cycles because of shear cracking. The increase in the $b$-value in the last cycles is attributed to attenuation of $\mathrm{AE}$ signals due to damage in the specimen. The computed AE based $b$-value can be correlated to physical measurements such as strain in tensile reinforcement and mid-span displacement as shown in Figure 4. It was observed that when the $b$-value reached 1.0 the midspan displacement was around 3.2 $\mathrm{mm}$. AE released during cycling loading of $\mathrm{RC}$ structures could be due to different sources such as crack opening and crack propagation or friction of existing crack surfaces which could occur during opening or closure of cracks. A discremination between sources of $\mathrm{AE}$ can be done by localization. 

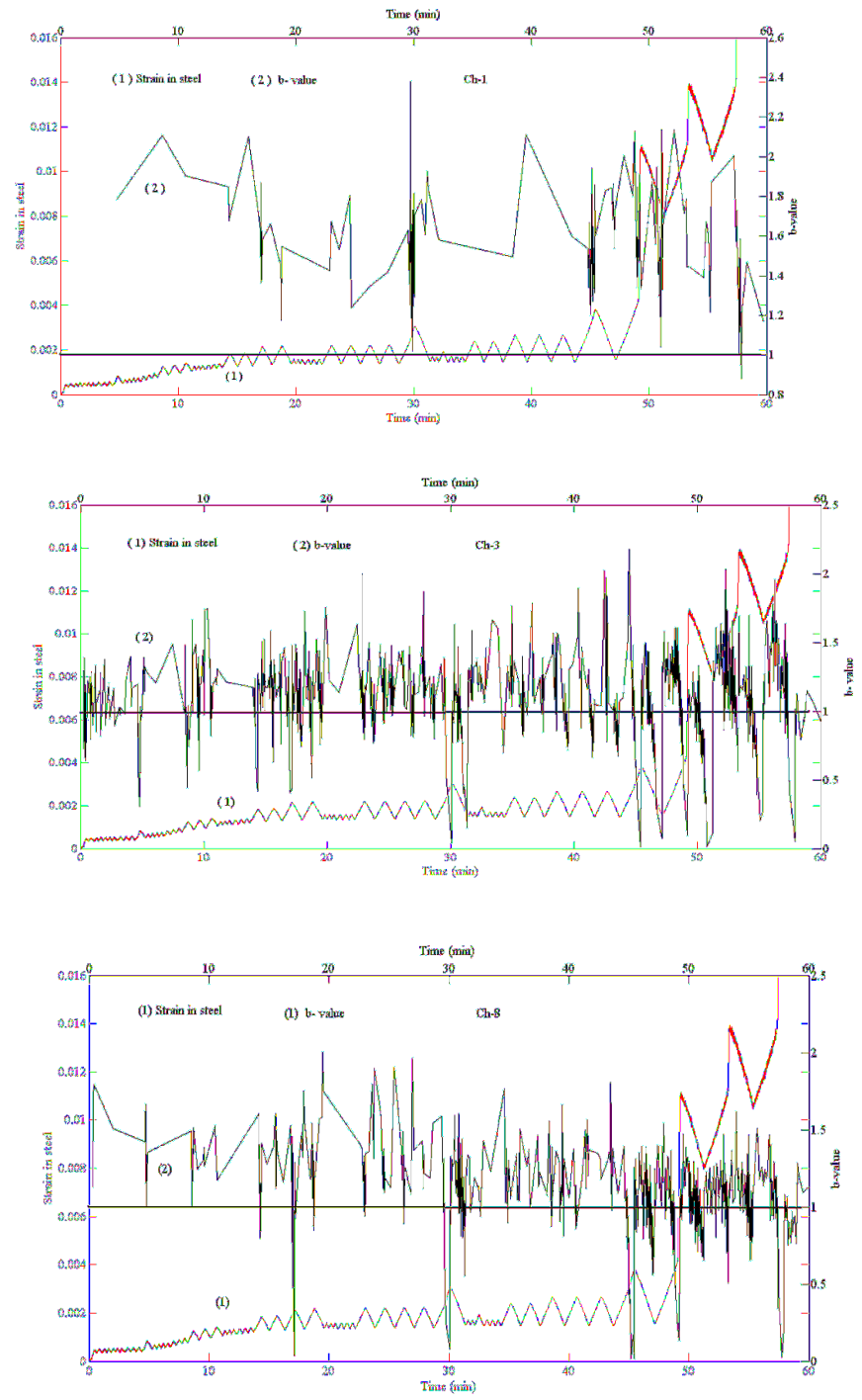

Figure 4: Variation of $b$-value with strain in steel recorded at $\mathrm{Ch}-3$, Ch-1 (shearing area) and $\mathrm{Ch}-8$ (at centre)

\subsection{Loading rate effect on $b$-value}

In case of low rate of loading, there is ample time for the damage to grow. Hence, there is a less scope of microcracks to develop and also less chances of spreading the micorcracks fast. It was observed the recorded AE hits are less when the rate of loading is high. The first crack appeared at higher load when the rate of loading is less.

The specimen yielded relatively quickly when the rate of loading is high. It was observed that the steel yielded more quickly with a higher loading rate, in terms of time, as the load isapplied over a shorter time frame. Also the recorded hits are less for the specimen tested with high rate of loadin, one can observe that the rate of occurrence of $\mathrm{AE}$ hits are more in case of LLR1 (tested with $6 \mathrm{kN} / \mathrm{s}$ loading rate) when compared with LC2M37 (tested with 4 $\mathrm{kN} / \mathrm{s}$ loading rate) specimen. Relatively the loading rate applied on LC2M37 specimen is small. The AE $b$-values are less for the specimen tested with high rate of loading. This may be due to release of high amplitude $\mathrm{AE}$ events.
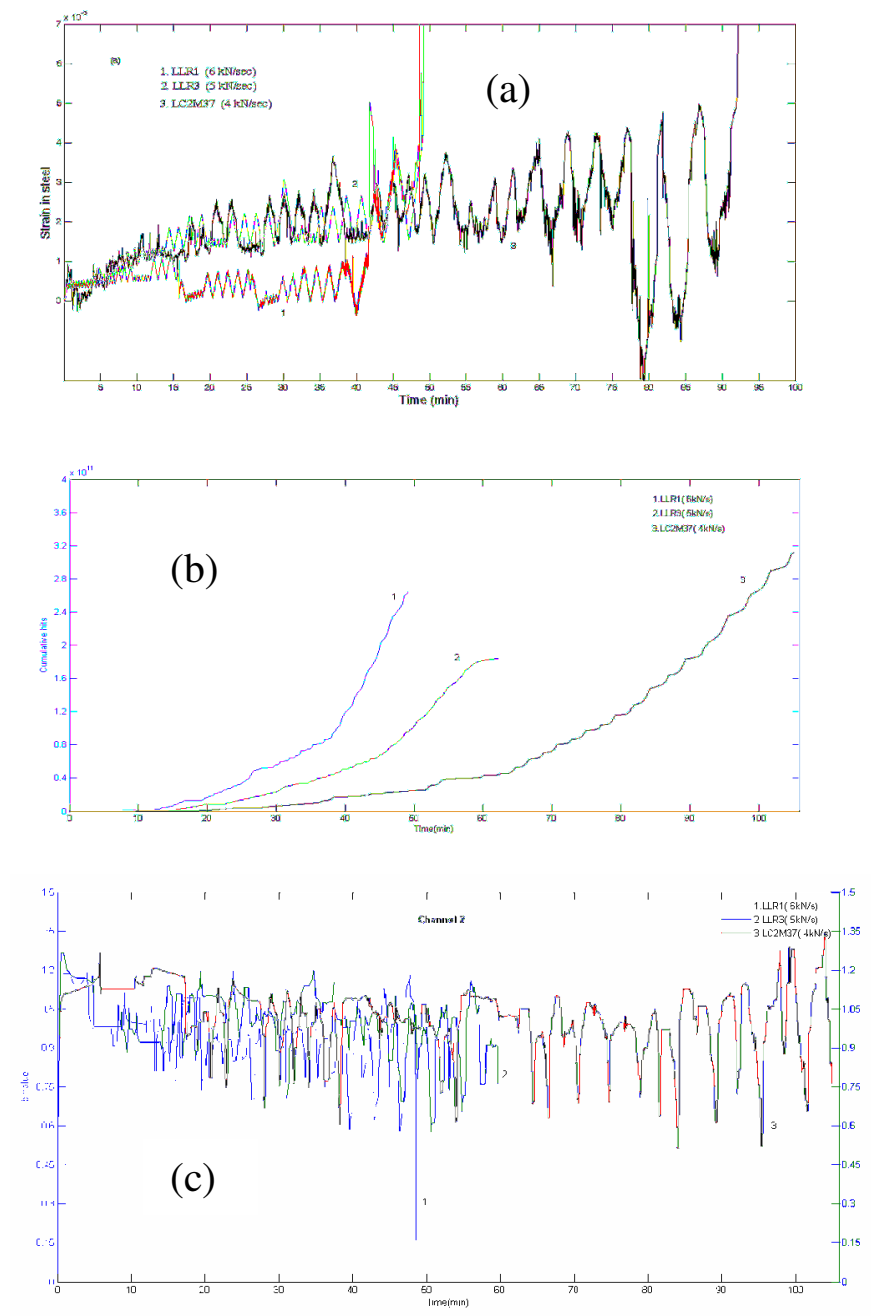

Figure 5: (a) Variation of strain in steel with time (b) Variation of cumulative AE hits with time. (c) Distinction in $b$-value with time due to change in rate of loading 
For three loading rates of $4 \mathrm{kN} / \mathrm{s}, 5 \mathrm{kN} / \mathrm{s}$ and 6 $\mathrm{kN} / \mathrm{s}$ on $\mathrm{RC}$ beam specimens, the times of occurrence of the lowest $b$-values vary as shown in Figure 5c. Higher AE activity such as large number of $\mathrm{AE}$ events per time and higher intensity events are also observed around the last loading phases. These observations further prove that the instance of damage initiation is predicted by the lowest $b$ value. Low $b$-value may be due to initiation of micro-cracks and cracks opening. The increase in $b$-value during the unloading in a cycle could be related to shear cracks development and crack sliding. However, the test specimen which is subjected to a lower loading rate of 4 $\mathrm{kN} / \mathrm{s}$ has shown some characteristic AE signatures while the sample LLR1 which was subjected to a loading rate of $6 \mathrm{kN} / \mathrm{s}$ seem to have undergone more damage in a short time relatively as inferred from the average amplitude, $b$-value, energy/ hit and cumulative energy counts. In case of LC2M37 test specimen, damage is less because of lower loading rate. And incase of LLR3 damage is intermediate since the rate of loading is also intermediate. Damage is more in LLR1 because of higher loading rate.

Rate of loading can accelerate the micro crack damage which is accompanied by the release of AE. If the rate of loading is too fast (more than what is suggested by the ASTM), there can be a surge or heavy rush of AE that the data logging equipment cannot cope up. In such a case the number of $\mathrm{AE}$ events or hits recorded would be less giving rise to higher $b$ values. The fluctuations in the $b$-value variation is more when the rate of loading is high. One can observe that the specimen LC2M37 underwent less damage at smaller rate of loading in terms of the data of $b$-value, AE energy per hit. From Figure $5 \mathrm{c}$ one can observe that there is a distinction in $b$-value with time due to change in rate of loading.

It was observed that when the loading rate is high, then the quick cracking development takes place because high energy events released, which leads to rapid fluctuations and also there was drops in the $b$-values. Also it was observed that the material behaves relatively more brittle at higher loading rates (or in higher strain rates), the $b$-values are lower in average as a few and strong cracking $\mathrm{AE}$ events with higher energy are created. But when the loading rate is low more $\mathrm{AE}$ and with less AE energy are released.

\subsection{Fluctuations of average frequency (AF) and rise angle (RA).}

The tensile mode of cracking which includes opposing movement of the crack sides, results in $\mathrm{AE}$ waveforms with short rise time and high frequency. On the contrary shear type of cracks result in longer $\mathrm{AE}$ waveforms, with low frequency and longer rise time. AF value for each load cycle decreases gradually as the loading progresses as shown in Figure 6 . When the AF of a signal is higher the crack can be classified as of tensile mode. The gradual decrease in AF shows the formation of the shear cracks at the final stage of the loading.

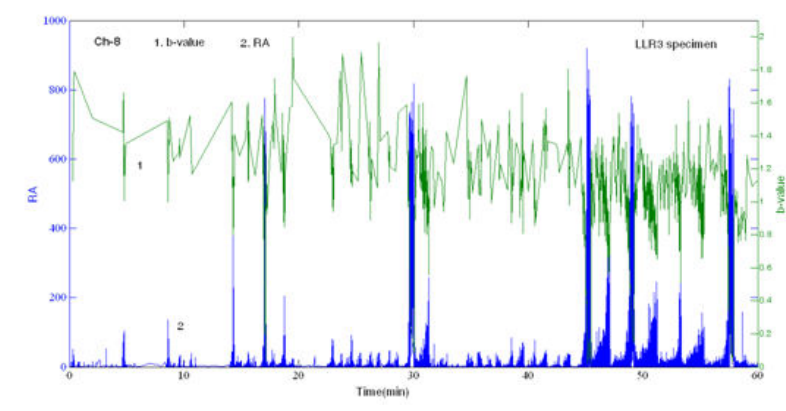

Figure 6: Variation of $b$-value with RA (LLR3 specimen)

Figure 6 shows the fluctuations of RA (rise time/amplitude) that could be temporary shift between small and large scale events and coincide with the drops of $b$-value. Rise time is observed to increase for the last loading cycles compared to the initial ones. This could be due to the formation of shear cracks. Shear cracks is relatively brittle in nature. Therefore fracture takes place suddenly and the rise time is relatively small. During the initial loading cycles the $\mathrm{AE}$ hits were of shorter rise time compared to the final loading cycles which had AE hits with longer rise time. Hence for the final cycles shear cracks are observed as the rise time is longer. It is observed that a 
sudden $b$-value drops when there is a rise in RA value. This could be due to formation of new crack or propagation of existing crack.

\subsection{Influence of compressive strength on the AE based $b$-values.}

Figure 7 shows the $b$-value variation for the specimens made out of the three different concrete mixtures. It was observed that there is a change in the $b$-values due to change in the compressive strength of concrete. AE based $b$ values decreased with an increase in stress for specimens made with concrete of $37 \mathrm{MPa}, 60$ $\mathrm{MPa}$ and $80 \mathrm{MPa}$. Therefore a decrease in $b$ value can be an indication of impending damage. Figure 9b shows the variation of $b$ value with mid-span displacement. $b$-value depends on the fracture process in RC structures. As the compressive strength of concrete increases, brittleness of the member also increases.

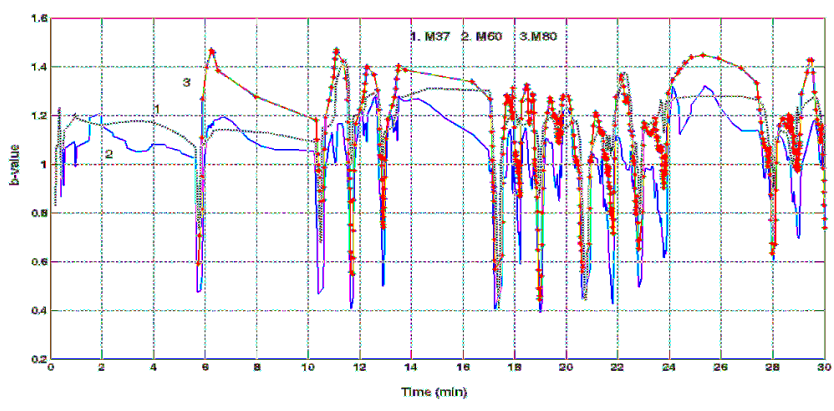

Figure 7: Variation of $b$-value with concrete strength

Due to brittleness of the material, high energy $\mathrm{AE}$ events release in less number hence low $b$ values. It is observed that at higher strains in steel at midspan the $b$-value decreased.

\subsection{Comparison of $b$-values with the damage parameter (D)}

Damage is a change in the current state or condition of a structural member that reduces its load carrying capacity. In RC structures, cracking reduce the load carrying capacity of a structural member [14]. Studies on crack formation and crack width are important.
Since fracture process in RC members may expose steel reinforcement to the environment which can lead to corrosion of reinforcement (or rebar). To ascertain the importance of the AE based $b$-value analysis in the damage evaluation, a comparison is made with the damage parameter (D) equal to $\sum 10^{3 \cdot\left(\frac{A d B}{20}\right)}$ and AE based $b$-value [15]. Here, the computed $b$ value varies with the damage parameter (D) as shown in Figure 8. And D values are in between 0 and 1.0. The scaling of frequencymagnitude distribution is affected by different loading conditions, then the $b$-value and its progress may also be affected by compressive strength of the concrete.

$\mathrm{AE}$ based $b$-values decreases with increase in damage, and damage of the material depends on concrete strength. It is observed that D is reaching 1.0 early at Ch-2 when compared to other channels. The reason may be at the $\mathrm{Ch}-2$

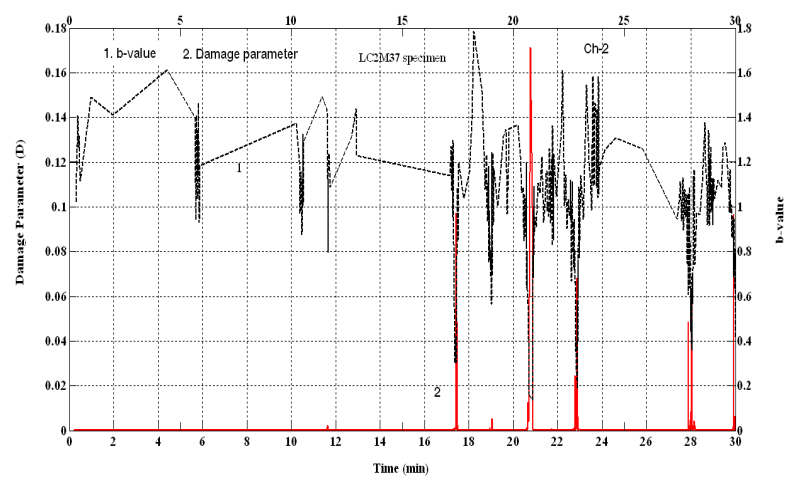

location, part of the RC beam has undergone the most sever deterioration.

Figure 8: Variation of damage parameter (D) with time

\subsection{Comparison of $b$-value with evolution of cracks developed in the test specimen}

Initially, $b$-values showed a clear pattern thus implying the formation of micro-cracks. As the fracture process progress further, the pattern was less clear implying the formation of the macro-cracks. There is a sharp decrease in the $b$-value at certain loading stages. The decrease in $b$-value represent the higher load and increase in damage. From this observation, the maximum $b$-value represents the microcracks formation and the macro-cracks are represented by the minimum $b$-value. 
Initially, the maximum trend increased in the loading phases of II to III with regard to the formation of the micro-crack. Secondly, the minimum trend shows a decreasing behavior until it reaches an absolute minimum near phase IV indicating the presence of macrocracks. The minimum $b$-value remains constant until any further cracks appear on the beam. The first stage where the micro-cracks are dominant and the macro-cracks start to appear, which could be visually observed on the beam. The second stage is where the cracks remain constant and visually no new cracks are formed. The final stage is where the macro-cracks open up as the beam tends to fail. It is observed that the micro-cracks (invisible) have many $\mathrm{AE}$ hits with low amplitude while the macro-cracks (visible) have less AE hits with high amplitude. Therefore, a high $b$-value indicates minor damage and a low $b$-value heavy damage.

The difficulty with the $\mathrm{AE}$ based $b$-value analysis is that it may not be possible to distinguish where the AE sources are come from and what are the source mechanisms. Also, the researchers working in structural engineering subject do not account for the attenuation between $\mathrm{AE}$ source and $\mathrm{AE}$ sensor. Gutenberg-Richter magnitude frequency relationship does not account for attenuation of $\mathrm{AE}$ waves. Attenuation in effect reduces the amplitudes of AE signals. It is equivalent to damping. Because the AE wave's amplitude get reduced due to attenuation, the slope of the line plotted between $\log _{10}(N)$ and $A_{d B}$ may become flatter and the $b$-value may become smaller than the actual value.

\section{CONCLUSIONS}

Based on the above results the given below major conclusions are drawn.

1. The AE based $b$-value studies are advantageous since it is not always easy to obtain 3-D source location data of high frequency $\mathrm{AE}$.
2. When the loading rate is faster, then the quick cracking development lead to quick fluctuations and drops in the $b$-value.

3. Concrete behaves relatively more brittle at higher loading rates, the $b$-values are lower in average as a few and strong cracking $\mathrm{AE}$ events are created, in contrast to more and weaker for low rate of loading.

4. AE based $b$-value analysis is useful in evaluating the damage level in RC structures in-situ, the instance of damage initiation can be predicted by the lowest $b$-value. And also when the rate of loading is high, the $b$-value is minimum.

5. A sudden drop in $b$-value occurred when there is a rise in RA value. This could be due to formation of new crack or propagation of existing crack.

6. $b$-value changes systematically during the different stages of the fracture process. AE events with low energy levels are more in number and events with higher energy levels are in less number released during fracture in $\mathrm{RC}$ beams.

7. The onset and occurrence of damage can be characterized by a sudden drop in the $b$-value. The instant fluctuations of $b$-value show the transition from micro-cracking to macrocracking, and therefore, could be a possible precursor to ultimate failure.

8. In case of incremental cyclic loading, during unloading stage large $b$-value was observed, and during loading stage low $b$-value was observed. It is possible that different channels show different $b$-values. Because the computed $b$-value depends on the AE recorded by the corresponding $\mathrm{AE}$ sensor. In $\mathrm{RC}$ structures, multiple cracks takes place and crack development varies from location to location. It may be posible to know the extent of damage near to the sensor locations based on $b$-value variation and the corresponding damage parameter (D) value.

\section{REFERENCES}

[1] Grosse, C.U. and Ohtsu, M., 2008. Acoustic emission testing. Springer, Heidelberg. 
[2] Gutenberg, B., and Richter, C. 1994. Frequency of earthquakes in California, Bulletin of Seismological Society of America, 34:185-188.

[3] Colombo S., Main, I.G., and Forde, M.C. 2003. Assessing damage of reinforced concrete beam using $b$-value analysis of acoustic emission signals. Journal of Materials in Civil Engineering 15:280-286.

[4] Farhidzadeh, A., Salvatore, S., Luna, B., and Whittaket A. 2013. Acoustic emission monitoring of a reinforced concrete shear wall by $b$-value based outlier analysis. Structural Health Monitoring 12: 3-13.

[5] Farhidzadeh, A., Ehsan Dehghan-Niri, Salamone, S., Luna, B., Whittaker, A. 2012. Monitoring crack propagation in reinforced concrete shear walls by acoustic emission. ASCE Journal of Structural Engineering 139: 04013010

[6] Aggelis, D.G., Shiotani, T., Momoki, S., and Hirama, A. 2009. Acoustic emission and ultrasound for damage characterization of concrete elements. ACI Materials Journal, 106: 509-514.

[7] Kurz, J.H., Finck, F., Grosse, C.U. and Reinhardt. H.W. 2006. Stress drop and stress redistribution in concrete quantified over time by the $b$-value Analysis. Structural Health Monitoring 5:69-81.

[8]E. Proverbio, V. Venturi and G. Campaneela. Damage assessment in post tensioned concrete viaduct by $b$-value and $\mathrm{I} b$ value analysis of AE signal. NDTCE'09, NonDestructive testing in civil engineering, Nantes, France, June 30- july $3^{\text {rd }}$. (2009).

[9] T. Schumacher, C. Higgins and S. Lovejoy. 2011. Estimating operating load conditions on reinforced concrete highway bridges with $b$ value analysis from acoustic emission monitoring. Structural Health Monitoring 10:17-32.
[10] Carpinteri, A., Lacidogna, G., and Puzzi, S. 2009. From criticality to final collapse: Evolution of the $b$-value from 1.5 to 1.0. Chaos Solitons and Fractals 41:843-853.

[11] Carpinteri, A., Lacidogna. G., and Pugno, N. 2006. Richter's laws at the laboratory scale interpreted by acoustic emission. Magazine of Concrete Research 58:619-625.

[12] Carpinteri A., Lacidogna G. and Manuello A. 2011. The $b$-value analysis for the stability investigation of the ancient athena temple in syracuse, Strain, 47: e243-e253.

[13] Vidya Sagar, R and Rao, M.V.M.S. 2014. An experimental study on loading rate effect on acoustic emission based $b$-values related to reinforced concrete fracture. Construction and building materials 70: 460472.

[14] Karihaloo, B.L. 1995. Fracture mechanics and structural concrete. Longman Scientific \& Technical, New York.

[15] S.J.D. Cox and P.G. Meridith, P.G. 1983. Microcracking formation and material softening in rock measured by monitoring acoustic emissions. International Journal of Rock Mechanics and Mining Sciences Geomechanics Abs. 30:11-24. 